\title{
ENERGY AND WATER CONSUMPTION CHARACTERIZATION OF PORTUGUESE INDOOR SWIMMING POOLS
}

\author{
Bruno J. Cardoso, Adélio R. Gaspar, José C. Góis, Eugénio Rodrigues \\ 1: ADAI, LAETA \& Department of Mechanical Engineering \\ Faculty of Sciences and Technology, University of Coimbra \\ Rua Luís Reis Santos, Pólo II, 3030-788 Coimbra, Portugal \\ e-mail: adelio.gaspar@dem.uc.pt; bruno.cardoso@adai.pt; jose.gois@dem.uc.pt; \\ eugenio.rodrigues@gmail.com
}

\begin{abstract}
Indoor swimming pools have high water and energy (electricity and natural gas) consumption levels due to the need to provide suitable thermal comfort conditions (temperature and relative humidity) to its occupants and to counterbalance losses (evaporation, ventilation, etc.). In Portugal, most of the swimming pool facilities belong to the municipalities and their operation represent a considerable financial burden. This work intent to characterize and benchmark the energy (electrical and thermal) and water consumption of five sport complexes with indoor swimming pools, located in two cities of the Centre of Portugal. The four most commonly performance indicators used in the literature were calculated and analyzed according to the operating time and services. Some measures are suggested to enhance the energy efficiency as well as to reduce the consumptions.
\end{abstract}

Keywords: Indoor swimming pools, Benchmarking, Performance Indicators, Energy Audit

\section{INTRODUCTION}

Within the building sector, sport centers have quite different energy requirements when compared with other types of buildings (services and residential). In fact, according to literature [1,2], sport facilities are better portrayed as processing plants rather than just as buildings because they are conceived to comply with the specific requirements of sports activities through the use of complex technical HVAC and water support systems.

The energy demand of sport centers depends on the sporting activity, the opening time, the period of year and the geographical location of the building [1,3]. For indoor swimming pool facilities, they are still influenced by usable area [4], water surface, age of the building, visitors, average water temperature and water usage [1].

Among the several types of sports facilities, indoor swimming pools have the highest energy consumption per usable area $\left(666.1 \mathrm{kWh} / \mathrm{m}^{2}\right)$, comparing for example with outdoor swimming pools $\left(102.7 \mathrm{kWh} / \mathrm{m}^{2}\right)$ or sports pavilions $\left(132.4 \mathrm{kWh} / \mathrm{m}^{2}\right)$ [5]. Indoor swimming pools have high water and energy consumption levels due to the need to provide appropriate thermal comfort conditions (temperature and relative humidity) to its occupants and to counterbalance losses (evaporation, ventilation, etc.). Typically, indoor swimming pools use two types of energy sources: thermal for pool water and space heating, and electricity to power water pumping systems, lighting systems, rotating equipment, air cooling and dehumidifying processes [1,3]. According to the literature, the biggest portion of energy consumption in an indoor swimming pool belongs to water heating (pool and showers), ventilation, room heating and operation of pumps [1].

It is estimated that there are over 100000 swimming pools facilities worldwide [6]. Thus, since these are energy-intensive installations, there is a high energy saving potential to be exploited [1]. As such, if attention is focused on water and energy performance of these facilities, several benefits such as energy and water conservation or greenhouse gas reductions can be accomplished [6]. Therefore, it is compulsory to assess the current energy use of these installations by a benchmarking where older and newer swimming pools can be compared [1].

In Portugal, most of the sport centers with indoor swimming pools are public buildings, belonging to municipalities. Thus, due to their substantial operational costs, mainly owing to large water and energy 
consumption levels, these facilities represent a considerable financial burden. Therefore, they represent good opportunities for implementing energy efficiency measures and achieving some noteworthy energy and financial savings. One way of analyzing/ranking the consumption of a given facility is by comparison with similar ones (benchmarking). However, as literature suggests, the choice of performance indicators should be done carefully because not only there is no consensus to which is the most suitable but also because the normalization metric could influence the benchmark by inducing errors, generating some uncertainty and leading sometimes to biased analysis [2].

The paper develops as follows. In section 2, the framework and methodology used in the energy audits are presented. In turn, in section 3 the consumption of the indoor swimming facilities is first analyzed globally and by energy sources (electricity and natural gas), and later normalized according to several metrics, such as usable area, water surface area and visitors. This normalization procedure was also applied to the water consumption. Still in section 3, some energy saving measures are identified.

\section{FRAMEWORK AND METHODOLOGY}

The analysis was performed in two stages. Firstly, five sport complexes with indoor swimming pools, located in Coimbra and Leiria cities, in the Centre region of Portugal, were selected and their annual water and energy (electricity and natural gas) consumption levels were surveyed. The survey was performed through a walk-through to the facilities to be acquainted with the main equipment and the processes related to water and energy consumption. It was collect several data associated to utility bills (water, electricity and natural gas), and the daily and monthly data record of consumption levels and visitors. Secondly, with the data collection, the five facilities were characterized, and some key performance indicators were calculated and analyzed. Additionally, several energy saving measures were pointed out and later examined.

Table 1 shows some characteristics of the swimming pools facilities examined in this study, namely the year of construction, number of pools per sport building, building usable area and pool surface area. The first four indoor swimming pools facilities are located in Coimbra, while the last one (CMPL) is located in Leiria. All facilities are more than 12 years old. However, it should be noted that the two oldest ones, PMC and CMPL, were submitted to requalification in 2014 and 2003 respectively, which influences their water and energy consumption.

Despite some similar features, there is a clear difference in dimension between the facilities analyzed, with the usable area varying from $1730 \mathrm{~m}^{2}$, for the smallest, to $8909 \mathrm{~m}^{2}$ for the largest. This difference in size is related not only to the difference of the number of existing swimming pools, but also to their surface areas. The lowest facility size (PMC) has the smallest pool surface area. However, the CMPL complex that has the highest number of swimming pools (three $-957 \mathrm{~m}^{2}$ ), is smaller than COPMC, which only has two pools $\left(1563 \mathrm{~m}^{2}\right)$.

Table 1 - Audited indoor swimming pools facilities.

\begin{tabular}{ccccc}
\hline $\begin{array}{c}\text { Sport } \\
\text { complex }\end{array}$ & $\begin{array}{c}\text { Year of } \\
\text { Construction }\end{array}$ & $\begin{array}{c}\text { Number } \\
\text { of Pools }\end{array}$ & $\begin{array}{c}\text { Building } \\
\text { Usable Area } \\
{\left[\mathbf{m}^{2}\right]}\end{array}$ & $\begin{array}{c}\text { Total Pool } \\
\text { Surface } \\
\text { Area }\left[\mathbf{m}^{2}\right]\end{array}$ \\
\hline PMC & $1991(2014)$ & 1 & 1730 & 263 \\
\hline PMLLC & 2005 & 2 & 2161 & 576 \\
\hline CPRA & 2004 & 2 & 3418 & 746 \\
\hline COPMC & 2005 & 2 & 8909 & 1563 \\
\hline CMPL & $1998(2003)$ & 3 & 5960 & 957 \\
\hline
\end{tabular}

\section{RESULTS AND DISCUSSION}

While the electricity is used for lighting systems, water-pumping systems and air-conditioning equipment, the natural gas is used for heating and air-conditioning of the swimming pool's surrounding space. Figure 1 shows that there is a clear discrepancy between the consumption verified by these two energy vectors in the buildings under study, with a higher dependence of natural gas in all the cases. The consumption of natural 
gas is in the range of $66 \%$ to $77 \%$ of the facility's total energy consumption, while the electricity achieves between $23 \%$ and $34 \%$.

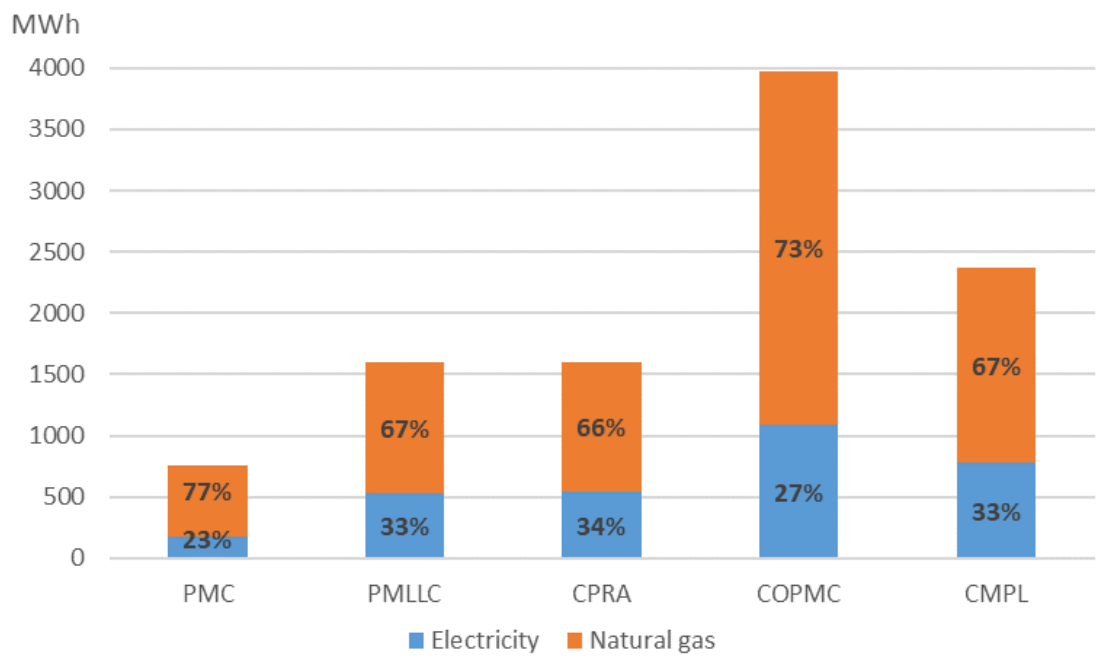

Figure 1 - Annual energy consumption (electricity and natural gas) of the audited complexes for a given year.

The COPMC and CMPL are the sport swimming pools complexes with the highest annual energy consumption, which is matched by both energy sources (electricity and natural gas). From these results, we are led to consider that the higher consumption is associated to higher size of the facilities, a superior water usage and a greater number of visitors. Nonetheless, these data should be thoroughly analyzed, because this difference in consumption may be linked to other factors not considered above. In Figure 2, the number of visitors and the building usable area show clearly the difference between the two above referred sport complexes and the other ones.

Although COPMC has higher values of usable area and water surface area, it presents a lower number of visitors when compared to the CMPL, which may be due to the competition by the number of swimming pools existing in the city of Coimbra.

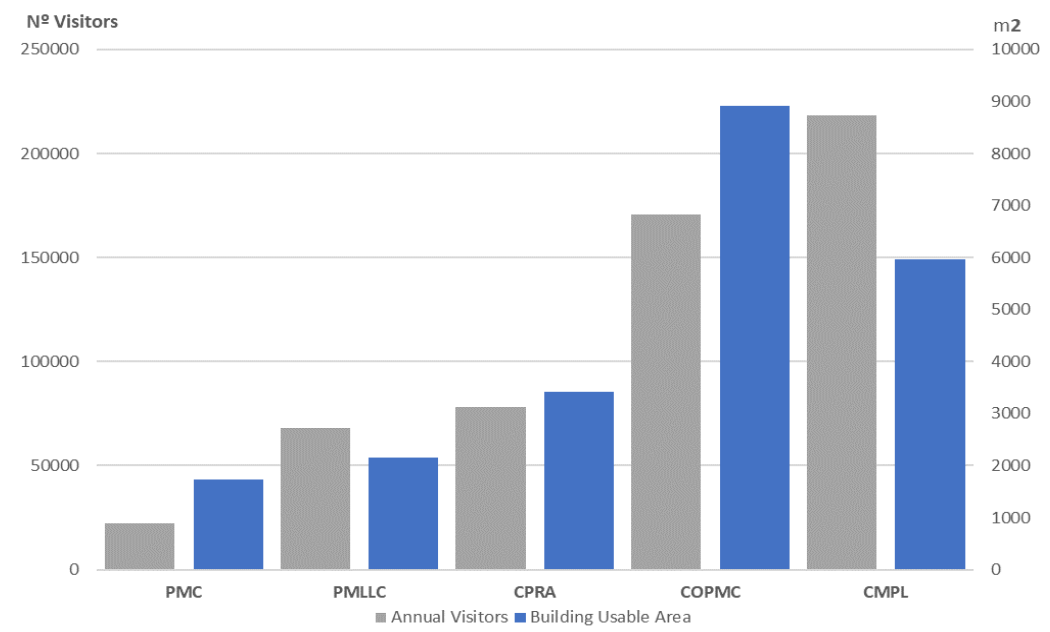

Figure 2 - Annual number of visitors and building usable area of the sample for a given year.

The natural gas boilers are the main equipment responsible for producing the thermal energy. The boilers produce the hot water used in shower facilities and supply the energy to the swimming pool heat exchangers and the air handling units (AHU). The chillers, pumps and fans are the main equipment responsible for the consumption of electricity. 


\subsection{Performance indicators}

According to literature [2], comparing similar indoor swimming pool facilities for benchmarking purposes can be conducted through performance indicators. However, there is no consensus as to which normalization metrics are the most appropriate. As such, the normalization metrics should be cautiously chosen as it can influence the benchmark process, leading to errors and biased conclusions due to the characteristics of these facilities (variety of services provided, water treatment systems, temperature and humidity level of spaces, evaporation due to swimming pool usage, etc.).

Kampel et al. [2], analyzed the most used indicators for benchmark the energy usage of swimming pools facilities. They verified that, from a statistical point of view, the two most commonly used normalization metrics, the usable area and water surface, are equally well suited. However, authors suggest using water surface since there is no agreement between authors as to take or not into account the technical areas in the value of the usable area, which may lead to distorted analysis. Besides, opposing to usable area, water surface is easy to attain with high accuracy and precision.

Thus, the usable area and water surface area were the normalization metrics used to compare the energy performance of the appraised facilities, allowing to obtain two energy performance indicators (Energy consumption per usable area and Energy consumption per water surface area) showed in Figure 3.

Observing the energy consumption normalized by these two metrics, it is verifiable that, although COMPC and CMPL have higher annual energy consumption levels, their performances are not worse than the rest indoor swimming pools sport complexes. Indeed, if paid attention to the energy consumption per usable area (Figure 3 on the left), the worst performance is presented by the PMLLC, followed in ascending order by the COMPC, CMPL and CPRA sport complexes. The best performance is achieved by PMC.

When observing the energy consumption per water surface area (Figure 3 on the right) the tendency is slightly different, showing smaller fluctuations between the values obtained. The best performance is still achieved by CPRA, which indicates that this sport complex presents a good energy performance when compared with the rest.

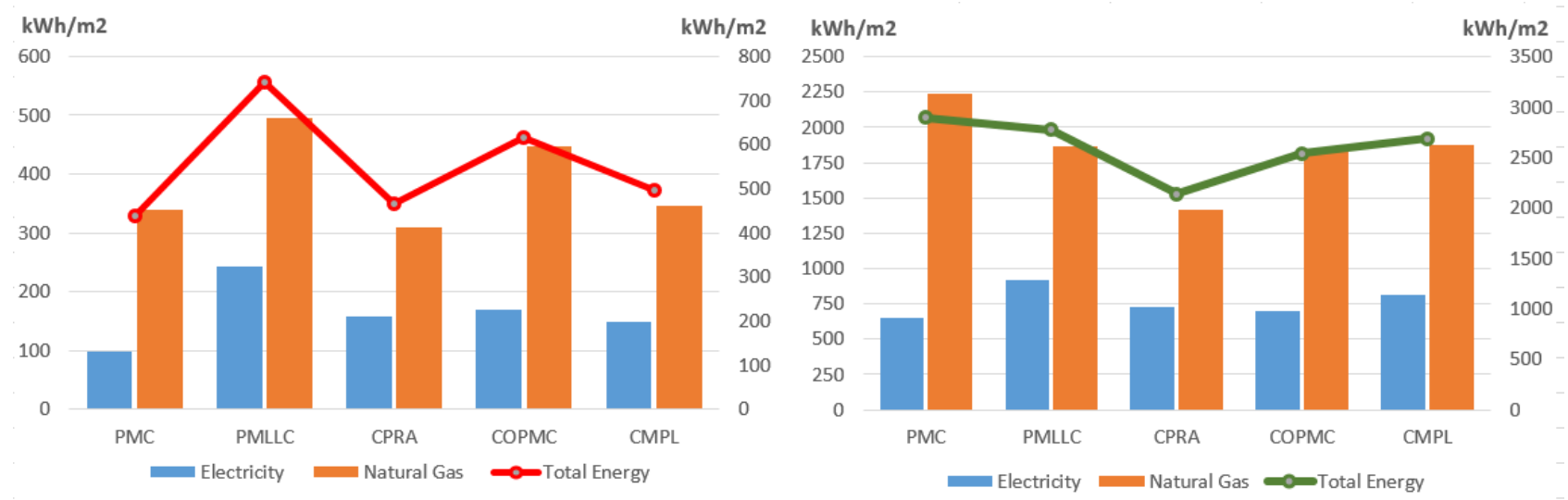

Figure 3 - Energy consumption per usable area (left) and energy consumption per water surface area (right).

In Figure 4 the results of the same metrics are presented for the water. Analyzing the water consumption per usable area (Figure 4 on the left) it is clearly shown that the smaller facilities present the highest values and so the lowest performance. The two facilities with the highest annual water consumption, COPMC and CMPL, present the best performances with the lowest values. When the water consumption per water surface area (Figure 4 on the right) is represented the results show a higher difference, but the best performance is still obtained by the COPMC, while the worst is attained by the PMC. For both metrics the best performance is achieved by COPMC. 

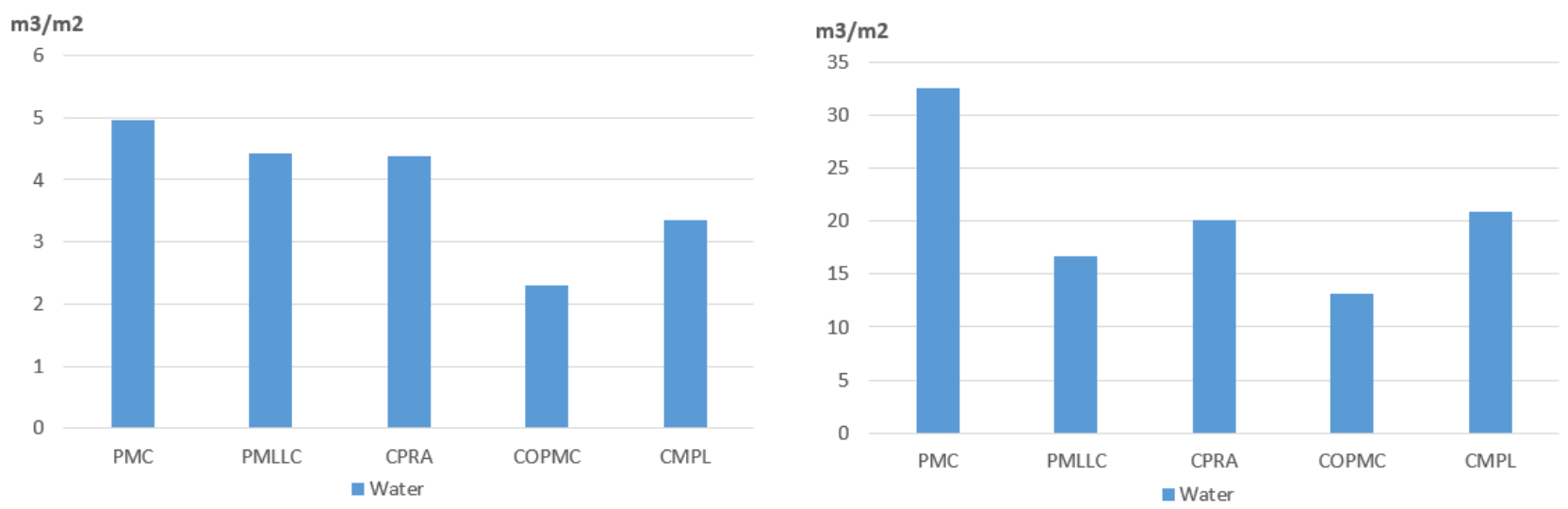

Figure 4 - Water consumption per usable area (left) and water consumption per water surface area (right).

There are other variables that can be used as normalization metrics (e.g., the building age, the average water temperature, the number of visitors and the water usage). Water usage and number of visitors are considered the variables more correlated with the energy consumption [2]. However, it is difficult to obtain accurate data about the number of visitors and water usage, so the usable area and the water surface area are commonly used [2].

As the number of visitors for each facility are assumed as reliable, the energy and water consumptions were normalized accordingly. Figure 5 shows the annual energy and water consumption normalized according to the number of visitors of each facility. In opposite to PMC, CMPL shows the lowest water and energy consumption per visitor, presenting the best performance.
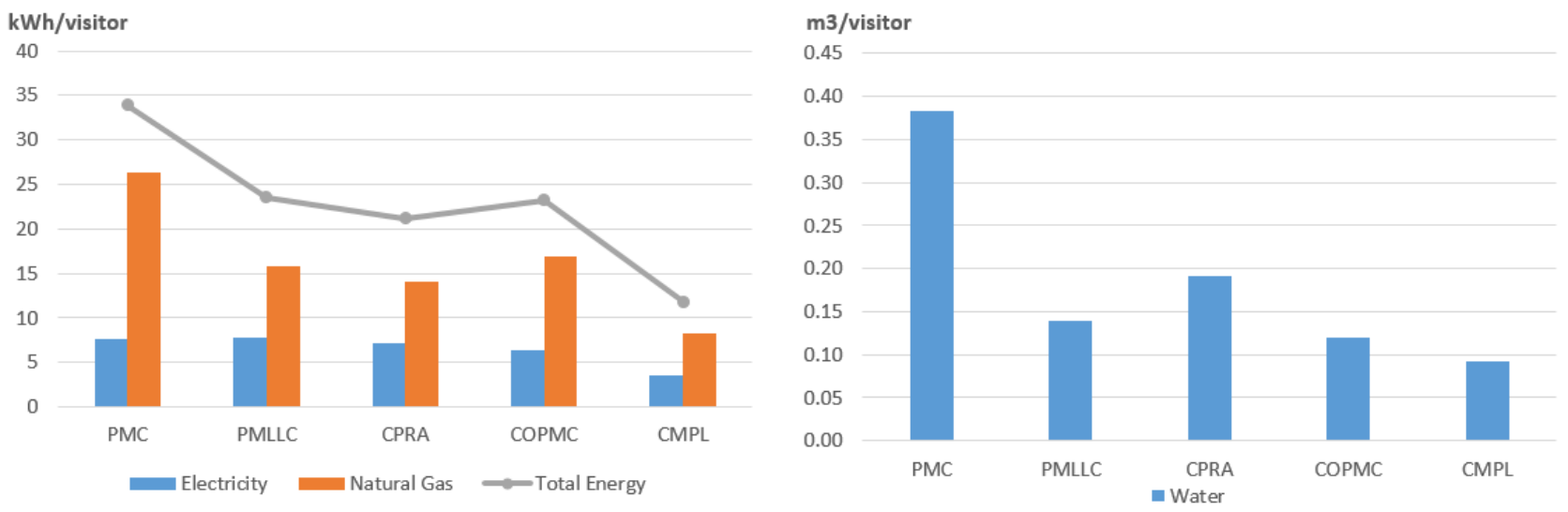

Figure 5 - Energy consumption per visitor (left) and water consumption per visitor (right).

\subsection{Energy saving measures}

For most of swimming pools facilities, an energy saving measure typically adopted is the application of a cover over the water surface during the time that it is not used, particularly during the night [6,7]. This measure allows to reduce the evaporation phenomenon [6-9] and the release of volatile substances to the air, such as chlorine, that affect negatively indoor air quality and often cause eye irritation or even asthma [6]. Additionally, it also reduces the air humidity in the surrounding area leading to lower necessity to dehumidifying and lower water reposition, which results in lower water and energy consumption levels [10]. In fact, none of the analyzed facilities has a cover, something that would counter the high humidity observed in the pool area during the colder months, a more prominent phenomenon in the PMC.

Another attractive measure is the application or repair of insulation of the tubes and storage vessels where hot fluid circulates. This application will reduce the thermal loss to the surrounding spaces [11], which depends of the temperature difference between the fluid and the surrounding spaces [12]. According to literature [13], the insulation repair is not commonly adopted despite being of simple implementation, with low-cost investment and significant energy savings (from $2 \%$ to $10 \%$ ). The lack of interest in the application of this measure is undeniable, since in the majority of the installations there were noticed insufficiencies of insulation, being CMPL the only in which the insulation is in better conditions. 
Replacing equipment currently used by other more efficient usually results in direct energy savings, if correctly used. This measure is justified by the age of the installations, over 12 years, which means that most of the equipment is susceptible of being replaced by more efficient ones, with lower energy consumption. Consequently, it can be suggested the substitution of the boilers (source of hot water production) by more advanced technology, such as condensation boilers that are more efficient [10]. Similar thought can be applicable for water pumping systems since that if they are correctly dimensioned, swapped by more efficient systems and adequately controlled, for example by variable frequency drives, their electricity consumption will be reduced [14].

Identical control procedure may be adopted for ventilation systems, enabling to adapt the systems' operation to the needs of each space, thereby reducing the overall energy consumption. It is also important the implementation of an adequate maintenance plan, not only corrective but also preventive, because it will allow equipment to operate in the adequate conditions, and to detect possible faults or waste of resources. In fact, this should be the first thing to implement due to its several benefits and low investment.

\section{CONCLUSIONS}

The analysis of five indoor swimming pool facilities in the Centre of Portugal showed that a simple comparison of annual water and energy consumption is not advisable because it is insufficient to draw accurate conclusions and may lead to biased or distorted assumptions.

If water and energy consumption values are normalized according to some metrics, such as the usable area, the water surface area or even the number of visitors, it will be possible to more accurately evaluate the performance of a specific facility. In fact, after performing standardization procedures, it was obtained convincing results which showed that indoor swimming pools with the lowest energy and water consumption was the one with the worst performance.

In order to improve the energy performance of these facilities the use of a cover on the pool surface during the inactivity period; the replacement of several equipment by more efficient ones; and, if possible, water pumping and ventilation systems controlled by variable speed drives must be evaluated. Despite these measures, an adequate maintenance plan should not be neglected because it allows beneficial results with low investment.

\section{ACKNOWLEDGMENTS}

This work has been financed by the Portuguese Foundation for Science and Technology (FCT) and by the European Regional Development Fund (FEDER) through COMPETE 2020 -- Operational Program for Competitiveness and Internationalization (POCI) in the framework of the research project Ren4EEnIEQ (PTDC/EMS-ENE/3238/2014, POCI-01-0145-FEDER-016760, and LISBOA-01-0145-FEDER-016760). Eugénio Rodrigues acknowledges the support provided by the FCT, under PostDoc grant SFRH/BPD/99668/2014. The authors are grateful to the students who were involved in the dissertations examined during this work, namely Pedro Sampaio, André Fontes, João Apolinário, Bruno Almeida and Eduardo Pedro.

\section{REFERENCES}

[1] Kampel W, Aas B, Bruland A. Energy-use in Norwegian swimming halls. Energy Build 2013;59:181-6. doi:10.1016/j.enbuild.2012.11.011.

[2] Kampel W, Carlucci S, Aas B, Bruland A. A proposal of energy performance indicators for a reliable benchmark of swimming facilities. Energy Build 2016;129:186-98. doi:10.1016/j.enbuild.2016.07.033.

[3] Trianti-Stourna E, Spyropoulou K, Theofylaktos C, Droutsa K, Balaras CA, Santamouris M, et al. Energy conservation strategies for sports centers: Part A. Sports halls. Energy Build 1998;27:109-22. doi:10.1016/S0378-7788(97)00040-6.

[4] International Organization for Standardization. ISO 9836: Performance Standards in Building Definition and Calculation of Area and Space Indicators 2011.

[5] Oliver-Solà J, Armero M, de Foix BM, Rieradevall J. Energy and environmental evaluation of municipal facilities: Case study in the province of Barcelona. Energy Policy 2013;61:920-30. doi:10.1016/j.enpol.2013.06.053.

[6] Duverge JJ, Rajagopalan P, Fuller R. Defining aquatic centres for energy and water benchmarking 
purposes. Sustain Cities Soc 2017;31:51-61. doi:10.1016/j.scs.2017.02.008.

[7] Mousia A, Dimoudi A. Energy performance of open air swimming pools in Greece. Energy Build 2015;90:166-72. doi:10.1016/j.enbuild.2015.01.004.

[8] Elsebaie $\mathrm{IH}$, Fouli H, Amin M. Evaporation reduction from open water tanks using palm-frond covers: Effects of tank shape and coverage pattern. KSCE J Civ Eng 2017;21:1-7. doi:10.1007/s12205-017-0539-4.

[9] Johansson L, Westerlund L. Energy savings in indoor swimming-pools: comparison between different heat-recovery systems. Appl Energy 2001;70:281-303. doi:10.1016/S0306-2619(01)000435.

[10] Zuccari F, Santiangeli A, Orecchini F. Energy analysis of swimming pools for sports activities: cost effective solutions for efficiency improvement. Energy Procedia 2017;126:123-30. doi:10.1016/j.egypro.2017.08.131.

[11] Kaynakli O. Economic thermal insulation thickness for pipes and ducts: A review study. Renew Sustain Energy Rev 2014;30:184-94. doi:10.1016/j.rser.2013.09.026.

[12] Kohlenbach P, Ackermann L, Mörtl K, Punzel G, Osborne J. Influence of oil-soaked insulation on the heat loss of thermal oil piping used in high-temperature solar cooling applications. Energy Procedia 2014;48:739-48. doi:10.1016/j.egypro.2014.02.086.

[13] ISR-UCoimbra, ADENE, ADEME. Guia Técnico Programa Motor Challenge - Soluções para melhorar os sistemas accionados por motores electricos. 2007.

[14] Hameiri Z, Spooner T, Sproul AB. High efficiency pool filtering systems utilising variable frequency drives. Renew Energy 2009;34:450-5. doi:10.1016/j.renene.2008.05.021. 